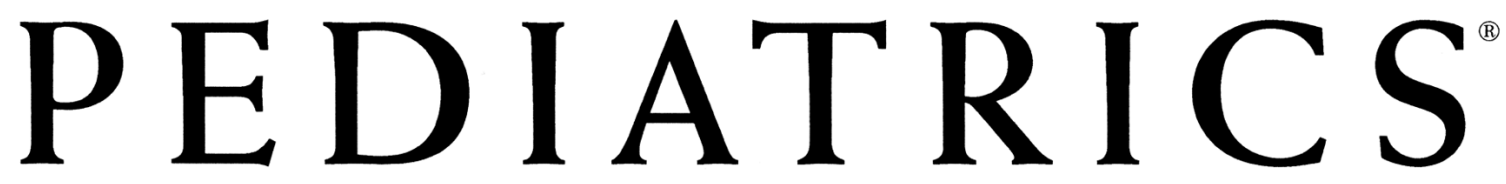

OFFICIAL JOURNAL OF THE AMERICAN ACADEMY OF PEDIATRICS

Kangaroo Transport Instead of Incubator Transport

Dieter Sontheimer, Christine B. Fischer and Kerstin E. Buch

Pediatrics 2004;113;920-923

DOI: $10.1542 /$ peds.113.4.920

The online version of this article, along with updated information and services, is located on the World Wide Web at:

http://www.pediatrics.org/cgi/content/full/113/4/920

PEDIATRICS is the official journal of the American Academy of Pediatrics. A monthly publication, it has been published continuously since 1948. PEDIATRICS is owned, published, and trademarked by the American Academy of Pediatrics, 141 Northwest Point Boulevard, Elk Grove Village, Illinois, 60007. Copyright ( 2004 by the American Academy of Pediatrics. All rights reserved. Print ISSN: 0031-4005. Online ISSN: 1098-4275.

\title{
American Academy of Pediatrics
}

DEDICATED TO THE HEALTH OF ALL CHILDREN ${ }^{\mathrm{m}}$ 


\title{
Kangaroo Transport Instead of Incubator Transport
}

\author{
Dieter Sontheimer, MD*; Christine B. Fischer, MD‡; and Kerstin E. Buch, RN*
}

\begin{abstract}
Objective. Compared with in utero transport, incubator transport for preterm infants has several disadvantages including instability during transport with increased mortality and morbidity, lack of adequate systems for securing the infant in the event of an accident, and separation of mother and infant. As a new kind of postnatal transportation that bears some analogy to in utero transport and may be safer than incubator transport, we investigated kangaroo transport, transporting the infant on the mother's or other caregiver's chest. This article presents a description and preliminary data for kangaroo transport.

Design. We conducted kangaroo transports of 31 stable preterm and term infants in different settings and recorded data regarding transport conditions and cardiorespiratory stability. Eighteen transports were back transfers, and 13 were transfers in. Twenty-seven transports were conducted by the mother, 1 by the father, 2 by nurses, and 1 by a doctor. Transport distance was 2 to 400 $\mathrm{km}$.
\end{abstract}

Results. Heart rate, respiratory rate, oxygen saturation, and rectal temperature remained stable during all kangaroo transports lasting 10 to 300 minutes. Weight at transport was 1220 to 3720 g. Parents felt very comfortable and safe and appreciated this method of transport.

Conclusions. Kangaroo transport promotes motherinfant closeness and might ameliorate several of the risks associated with incubator transport. Pediatrics 2004;113: 920-923; kangaroo, transport, incubator, preterm, back transfer.

$\mathrm{V}$ ery low birth weight infants who are transported directly after birth have an increased risk of intraventricular bleeding compared with infants who are not transported. This may be explained by mechanical effects such as shaking or vibration of the head and by instability of temperature and blood pressure during the incubator transport. ${ }^{1}$ Moreover, the organization and safety of the transport system has been questioned in a recent overview by Field et $\mathrm{al}^{2}{ }^{2}$ who summarized the experiences in the United Kingdom and stated that most of the available transport systems have serious problems, especially in the event of an accident. They reported that the standard devices used to secure transport incubators are totally inadequate and that there are no adequate safety devices for securing the infant within the incubator during the journey.

From *Children's Hospital, Wernigerode, Germany; and ‡Children’s Hospital, Boston, Massachusetts.

Received for publication Dec 26, 2002; accepted May 8, 2003.

Reprint requests to (D.S.) Kinderklinik, Steinbergstrasse 1, 38855 Wernigerode, Germany. E-mail: dieter.sontheimer@harz-klinikum.de

PEDIATRICS (ISSN 0031 4005). Copyright (C) 2004 by the American Academy of Pediatrics.
Kangaroo care (skin-to-skin, chest-to-chest holding of the infant between the mother's breasts) of preterm infants in the hospital has been shown to improve or maintain cardiorespiratory stability, ${ }^{3-6}$ oxygen and energy expenditure, ${ }^{7}$ confidence and psychological stability of the mother, ${ }^{8}$ and preterm infant behavior development. ${ }^{9,10}$ According to a Cochrane review, ${ }^{11}$ kangaroo care seems to reduce severe infant morbidity, but well-designed, randomized, controlled trials of this intervention are still needed.

Because kangaroo transport means continuous kangaroo care during transport, the cardiorespiratory system might be more stable than during incubator transport. During incubator transports, the transfer of the infant in and out of the transport incubator (and especially the transfer and securing of the heavy transport incubator into and out of the ambulance) is often connected with swift and rough movements. Kangaroo transport might ameliorate much of this jarring motion. In addition, kangaroo transport might improve the security of the infant by fastening the infant to the mother and the mother to the emergency gurney. Kangaroo transport might be a possibility to maintain mother-infant contact after birth and to improve parent-infant bonding. However, it might not be appropriate for critically ill infants, who need repeated handling and therapeutic interventions during transport.

The purpose of this article is to describe our procedure and present results of our kangaroo transports of stable preterm and term infants in different settings.

\section{INFANTS}

From April to October 1997, 11 premature infants were transported in Heidelberg, Germany, in the kangaroo position with their mothers (transports 1, 2, 5, 7, 8, 10-12, and 17) or female nurses (transports 9 and 16) when parents were not available. In Wernigerode, Germany, from November 2000 to January 2003, 20 preterm and term infants were transported in the kangaroo position by their mothers, the father (transport 3), or one of the authors (D.S., transport 21). Two transports were by helicopter (transports 14 and 18), and all other transports were by ambulance. All parents provided informed consent before transport.

The gestational age of the infants ranged from 26 to 41 weeks, the age at transport ranged from 1 hour to 79 days, and the weight at this time ranged from 1220 to $3720 \mathrm{~g}$ (Table 1). Eighteen kangaroo transports were back transfers to regional children's hospitals closer to their parents' home (transports 1, 3-6, 8, 13, 14, and 18), within Heidelberg (transports 2, 7, 9-12, 16, and 17), or within Wernigerode (transport 15). Thirteen transports were transfers in from either the Women's Hospital in a neighboring town without neonatology (transports 19, 20, 22-25, and 27-31) or the Women's Hospital in Wernigerode (transports 21 and 26) to the neonatal unit in Children's Hospital in Wernigerode.

The transport distance was $>50 \mathrm{~km}$ for 9 transports, 35 to $40 \mathrm{~km}$ 
TABLE 1. Range and Median of Gestational Age, Weight and Age at Transport, and Distance and Time of Transport for All Infants $(n=31)$

\begin{tabular}{lcc}
\hline & Range & Median \\
\hline Gestational age & $26-41 \mathrm{wk}$ & $35 \mathrm{wk}$ \\
Weight at transport & $1220-3720 \mathrm{~g}$ & $1970 \mathrm{~g}$ \\
Age at transport & $1 \mathrm{~h}$ to $79 \mathrm{~d}$ & $17 \mathrm{~d}$ \\
Distance of transport & $2-400 \mathrm{~km}$ & $35 \mathrm{~km}$ \\
Time for transport & $10-300 \mathrm{~min}$ & $40 \mathrm{~min}$ \\
\hline
\end{tabular}

for 11 transports, $4 \mathrm{~km}$ for 3 transports, and $2 \mathrm{~km}$ for 8 transports (Tables 2 and 3). The longest journey was $400 \mathrm{~km}$ (transport 13); the family had just changed their place of residence.

The time needed for transport was 10 to 20 minutes for the short transports and 60 to 300 minutes for the 9 long-distance transports. During transport, infants 1 and 2 received $25 \%$ to $30 \%$ oxygen because of bronchopulmonary dysplasia; infants 2, 7, 8, 10, 13,16 , and 28 received intravenous fluids; and 13 infants had a nasogastric tube in place (during 2 long-distance transports [ 8 and 13], formula was given slowly through this tube [ $40 \mathrm{~mL}$ in 20 minutes]).

\section{METHODS}

The mother, father, nurse, or doctor was positioned $10^{\circ}$ to $60^{\circ}$ semiupright on a portable gurney. Under the back of the caregiver laid a long, broad piece of fabric (infant-carrying sling by Didymos), with the ends left out to both sides. The caregiver then was secured to the gurney by straps, preferably in a suspender-like arrangement (Figs 1-6). The infant was placed on the chest of the caregiver in kangaroo position. The fabric was wrapped around the caregiver and infant in a sling-like fashion such that it covered the whole body of the infant securely. It was tied in a firm knot on the side to the mother (Figs 1-3). An additional blanket was placed over the mother and infant during transport to provide warmth (Figs 3 and 4). All infants were accompanied by a neonatal nurse and a neonatologist. Two transports were by helicopter (Fig 6), and 29 were by ambulance.

Infant monitoring of heart rate and respiratory rate was performed continuously with electrodes placed on the infant's back. ${ }^{12}$ Oxygen saturation was measured continuously by pulse oximetry. Intravenous fluids and additional oxygen were given if needed (Fig 1). Physiologic parameters were recorded manually every 5 minutes throughout transport according to standard transport protocols. Rectal temperature was measured for most of the cases before starting and directly after arriving (and monitored continuously during transports 12,16 , and 17).
Caregiver-infant pairs were transported in a standard, unheated ambulance or in standard helicopter environment; the environmental temperature was $16^{\circ} \mathrm{C}$ to $30^{\circ} \mathrm{C}$.

\section{RESULTS}

All infants were kept in the kangaroo position on the chest of their mothers, fathers, nurses, or doctors during the entire transport. Heart rate, respiratory rate, and oxygen saturation remained stable during the transport (Tables 2 and 3). In infant 8, heart rate increased from 130 to 165 beats per minute after 1 hour of transport. This was probably caused by increased body temperature, because the heart rate dropped to the initial level after removal of the additional blanket. Rectal temperature after arrival was between $36.5^{\circ} \mathrm{C}$ and $37.4^{\circ} \mathrm{C}$ for all infants. During 3 transports, temperatures were measured continuously, and regulation of the body temperature was accomplished easily by either adding or removing a blanket.

Crying and agitated behavior was never observed by the attending neonatologist. In 3 cases, a neonatologist or a nurse held the infant for kangaroo transport. No substantial differences were observed for these special conditions (transports 9, 16, and 21). Like the parents, the health care professionals reported that the shaking motion of the car during transport seemed greatly decreased for the infant through the position on the adult body. All parents appreciated being able to stay with their infants during the transport, reporting that they felt comfortable, safe, and happy to be able to provide personal transport for their infants.

\section{DISCUSSION}

Because of better outcome for inborn infants, regionalization of perinatal care with in utero transport is common when special care is needed immediately after birth. Neonatal transports are still required, however, when transport in utero is not possible or if

TABLE 2. Kangaroo Transport for Back Transfers of Infants $(n=18)$

\begin{tabular}{|c|c|c|c|c|c|c|c|c|c|c|c|}
\hline $\begin{array}{l}\text { Case } \\
\text { No. }\end{array}$ & $\begin{array}{l}\text { Gestational } \\
\text { Age, wk }\end{array}$ & $\begin{array}{c}\text { Birth } \\
\text { Weight, } \\
\text { g }\end{array}$ & $\underset{\mathrm{d}}{\text { Age, }}$ & $\begin{array}{l}\text { Weight, } \\
\text { g }\end{array}$ & $\begin{array}{c}\text { Distance, } \\
\text { km }\end{array}$ & $\begin{array}{c}\text { Time, } \\
\text { min }\end{array}$ & $\begin{array}{l}\text { Heart Rate, } \\
\min ^{-1}\end{array}$ & $\begin{array}{c}\text { Respiration } \\
\text { Rate, } \\
\text { min }^{-1}\end{array}$ & $\begin{array}{c}\text { Oxygen } \\
\text { Saturation, } \\
\%\end{array}$ & $\begin{array}{l}\text { Temperature } \\
\text { (Start), }{ }^{\circ} \mathrm{C}\end{array}$ & $\begin{array}{l}\text { Temperature } \\
\text { (Arrival), }{ }^{\circ} \mathrm{C}\end{array}$ \\
\hline 1 & 26 & 870 & 43 & 1970 & 110 & 100 & $135-155$ & $40-50$ & 91-99 & 36.8 & 37.2 \\
\hline 2 & 27 & 790 & 31 & 1220 & 2 & 15 & $140-150$ & $40-60$ & $92-99$ & 36.9 & 36.9 \\
\hline $3^{*}$ & 28 & 1000 & 32 & 1580 & 90 & 80 & $145-175$ & $50-80$ & $92-98$ & 36.5 & 37.2 \\
\hline 4 & 28 & 1290 & 31 & 1740 & 90 & 80 & $135-155$ & $45-75$ & $96-100$ & 37.1 & 37.4 \\
\hline 5 & 28 & 1390 & 26 & 1640 & 60 & 60 & $130-160$ & $35-45$ & 93-100 & 36.5 & 37.1 \\
\hline 6 & 29 & 540 & 79 & 1340 & 94 & 70 & $150-180$ & $60-80$ & 97-99 & $\ldots$ & 36.9 \\
\hline 7 & 29 & 1320 & 18 & 1510 & 2 & 10 & $135-165$ & $35-50$ & 94-98 & 36.6 & 36.7 \\
\hline 8 & 29 & 1410 & 22 & 1550 & 180 & 150 & $130-165$ & $40-50$ & 95-98 & 36.8 & 36.9 \\
\hline $9+$ & 30 & 1520 & 4 & 1480 & 2 & 10 & $140-160$ & $50-60$ & $92-99$ & 36.6 & 36.5 \\
\hline 10 & 31 & 1470 & 8 & 1530 & 2 & 10 & $130-145$ & $40-55$ & 95-99 & 36.5 & 37.0 \\
\hline 11 & 32 & 1320 & 17 & 1400 & 2 & 10 & $150-160$ & $40-60$ & 95-100 & 36.7 & 37.1 \\
\hline 12 & 32 & 1660 & 5 & 1650 & 2 & 10 & $140-150$ & $45-55$ & 94-98 & 36.6 & 36.7 \\
\hline 13 & 34 & 1760 & 9 & 1690 & 400 & 300 & $125-150$ & $40-55$ & 94-99 & 36.8 & 36.8 \\
\hline 14 & 34 & 2530 & 21 & 2740 & 110 & 30 & $130-145$ & $40-60$ & 96-99 & 36.6 & 37.1 \\
\hline 15 & 35 & 1740 & 15 & 1940 & 4 & 20 & $120-140$ & $40-50$ & 96-99 & $\ldots$ & $\ldots$ \\
\hline $16 t$ & 35 & 1890 & 7 & 1785 & 2 & 10 & 140-155 & $35-45$ & $92-96$ & 36.8 & 36.9 \\
\hline 17 & 36 & 1710 & 8 & 1635 & 2 & 10 & 130-150 & $45-55$ & 96-99 & 36.4 & 36.9 \\
\hline 18 & 39 & 3470 & 17 & 3700 & 180 & 40 & 110-130 & $30-40$ & 96-100 & 37.0 & 37.4 \\
\hline
\end{tabular}

... indicates that data were not available. All transports were with the mother except where noted.

* Transport was with the father.

t transport was with a nurse. 
TABLE 3. Kangaroo Transport for Transfers in of Infants $(n=13)$

\begin{tabular}{|c|c|c|c|c|c|c|c|c|c|c|c|}
\hline $\begin{array}{l}\text { Case } \\
\text { No. }\end{array}$ & $\begin{array}{c}\text { Gestational } \\
\text { Age, wk }\end{array}$ & $\begin{array}{c}\text { Birth } \\
\text { Weight, } \\
\mathrm{g}\end{array}$ & $\begin{array}{c}\text { Age, } \\
\mathrm{d}\end{array}$ & $\begin{array}{l}\text { Weight, } \\
\text { g }\end{array}$ & $\begin{array}{l}\text { Distance, } \\
\mathrm{km}\end{array}$ & $\begin{array}{c}\text { Time, } \\
\text { min }\end{array}$ & $\begin{array}{l}\text { Heart Rate, } \\
\min ^{-1}\end{array}$ & $\begin{array}{c}\text { Respiration } \\
\text { Rate, } \\
\text { min }^{-1}\end{array}$ & $\begin{array}{c}\text { Oxygen } \\
\text { Saturation, } \\
\%\end{array}$ & $\begin{array}{c}\text { Temperature } \\
\text { (Start), }{ }^{\circ} \mathrm{C}\end{array}$ & $\begin{array}{l}\text { Temperature } \\
\text { (Arrival), }{ }^{\circ} \mathrm{C}\end{array}$ \\
\hline 19 & 35 & 2070 & 1 & 2070 & 35 & 40 & $130-160$ & $50-75$ & 95-100 & 37.0 & 37.2 \\
\hline 20 & 36 & 2710 & 18 & 2540 & 35 & 40 & 130-145 & $40-60$ & 97-100 & 36.8 & 36.9 \\
\hline $21^{*}$ & 36 & 2850 & 1 & 2850 & 4 & 20 & $125-150$ & $55-80$ & 93-97 & 36.7 & 37.0 \\
\hline 22 & 37 & 2980 & 8 & 2780 & 35 & 40 & $120-140$ & $45-60$ & 96-99 & $\ldots$ & $\ldots$ \\
\hline 23 & 38 & 3060 & 24 & 3000 & 35 & 40 & 115-130 & $40-55$ & 98-100 & 37.1 & 36.8 \\
\hline 24 & 39 & 2950 & 1 & 2950 & 35 & 40 & $100-125$ & $35-45$ & $97-100$ & $\ldots$ & $\ldots$ \\
\hline 25 & 39 & 3400 & 27 & 3260 & 35 & 40 & 90-120 & $30-50$ & $96-100$ & $\ldots$ & 36.9 \\
\hline 26 & 39 & 3440 & 5 & 3500 & 4 & 20 & 95-115 & $30-50$ & 97-99 & $\ldots$ & $\ldots$ \\
\hline 27 & 39 & 4120 & 36 & 3720 & 35 & 40 & 140-155 & $35-55$ & 95-100 & 37.0 & 37.3 \\
\hline 28 & 40 & 2720 & 9 & 2720 & 35 & 40 & $90-120$ & $45-70$ & $93-99$ & $\ldots$ & 36.8 \\
\hline 29 & 40 & 2990 & 12 & 2835 & 35 & 40 & $80-110$ & $30-50$ & 96-99 & 36.9 & 37.3 \\
\hline 30 & 40 & 3900 & 72 & 3670 & 35 & 40 & 95-110 & $35-50$ & 97-100 & 37.0 & 37.0 \\
\hline 31 & 41 & 3700 & 4 & 3430 & 40 & 50 & $100-125$ & $30-50$ & 97-100 & 36.6 & 36.7 \\
\hline
\end{tabular}

... indicates that data were not available. All transports were with the mother except where noted.

* Transport was with a doctor.

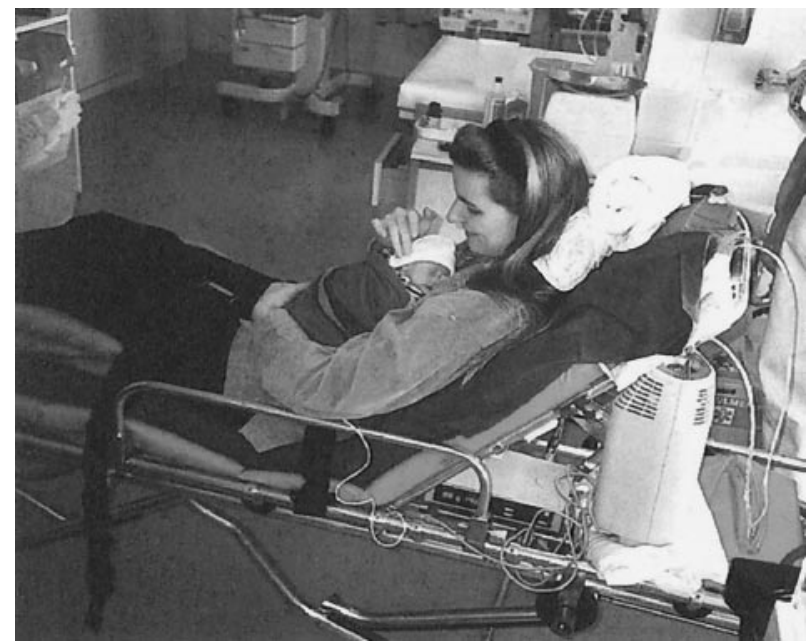

Fig 1. Mother with infant before kangaroo transport. The mother is fixed to a portable gurney by straps, with the upper part of her body at $60^{\circ}$ semiupright. The infant is fixed to her with a broad infant-carrying sling, with liquid oxygen and the monitor positioned on the head end of gurney.

the infants have to be transported from the perinatal center to a continuous care unit in another children's hospital (back transfer). Although kangaroo care has been implemented in several countries with very promising outcomes, ${ }^{13-15}$ kangaroo transport as an alternative to incubator transport has not been documented before.

Our preliminary results show that kangaroo transport of stable preterm and term infants can be performed over a short or long distance without compromising the physiologic stability of the infant. It provides a secure form of transport that simultaneously promotes maternal-infant closeness. Continuous monitoring is performed as reliably as in an incubator. The finding of cardiorespiratory and thermal stability during transport was not surprising, because the infants were in a stable condition before transport, and previous studies have shown that kangaroo care at home or in the hospital is safe. ${ }^{16,17}$ Additional studies on larger groups of infants can determine whether other physiologic parameters (eg, energy expenditure) of the infants remain as stable

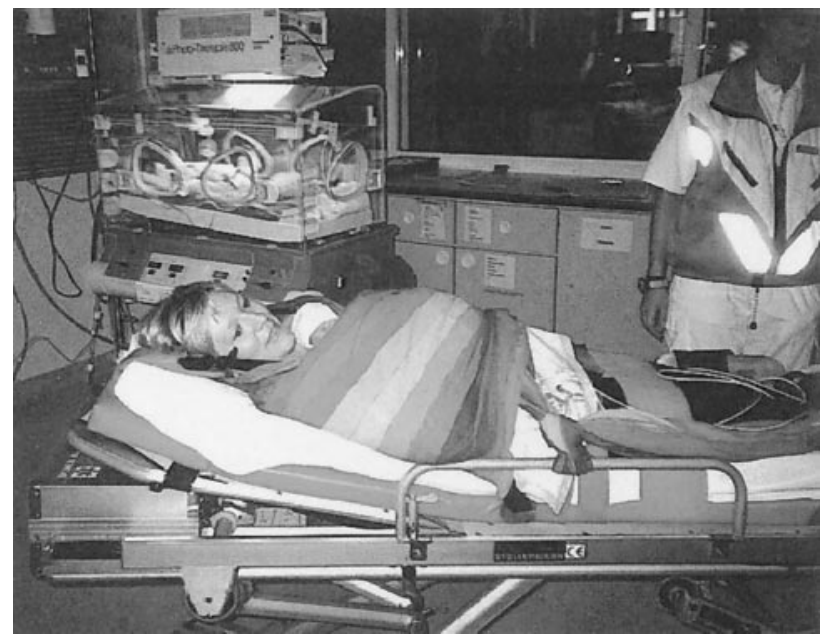

Fig 2. Mother with infant before kangaroo transport (back transfer from a neonatal intensive care unit). The infant is in kangaroo position on the mother's chest. The fabric is wrapped around the caregiver and infant in a sling-like fashion such that it covers the whole body of the infant securely.

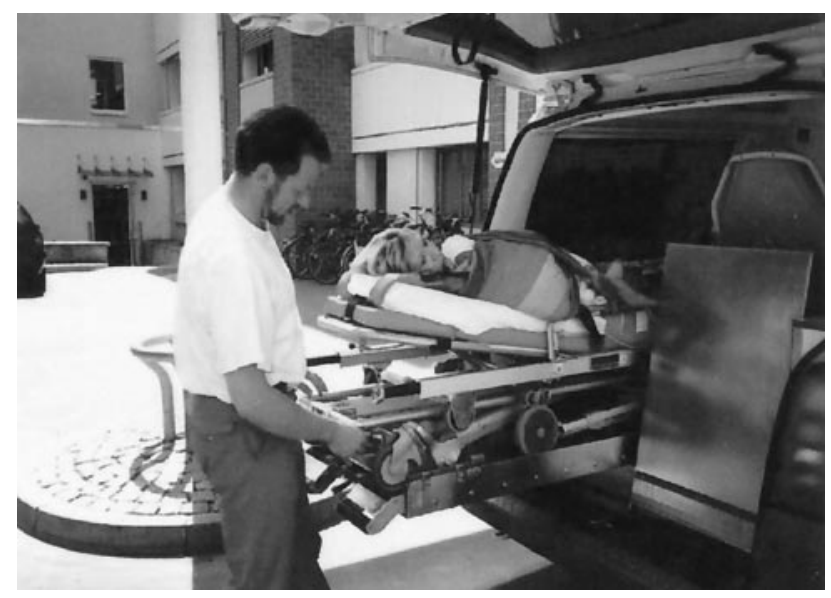

Fig 3. Mother with infant at arrival after kangaroo transport in an ambulance over a long distance (400 km, 5 hours).

during kangaroo transport as they are during routine kangaroo care.

The infants were secured with caregivers during the transport. In the event of an accident, kangaroo 


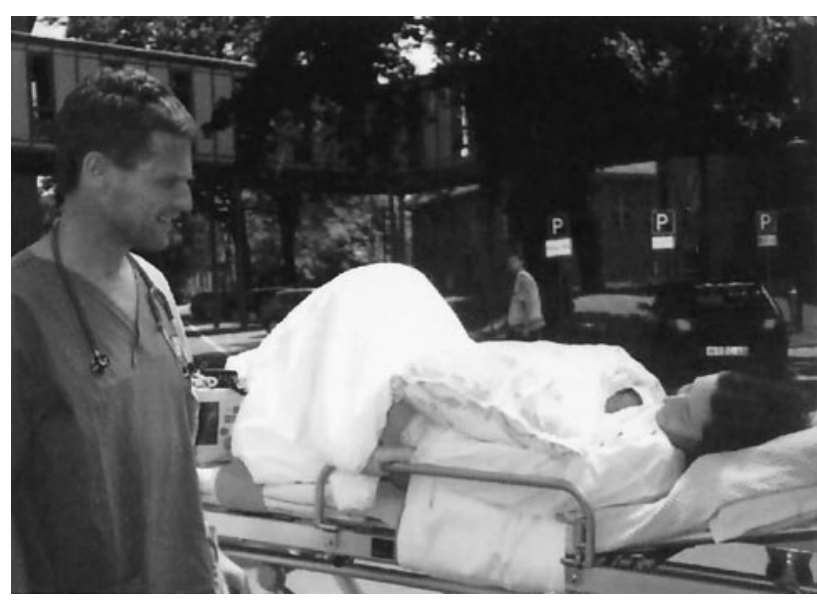

Fig 4. Mother with infant after kangaroo transport (40 minutes). An additional blanket is placed on top of the mother and infant. Shown is a transfer in 1 hour after birth because of tachydyspnea (35 weeks' gestational age, $2070 \mathrm{~g}$ ).

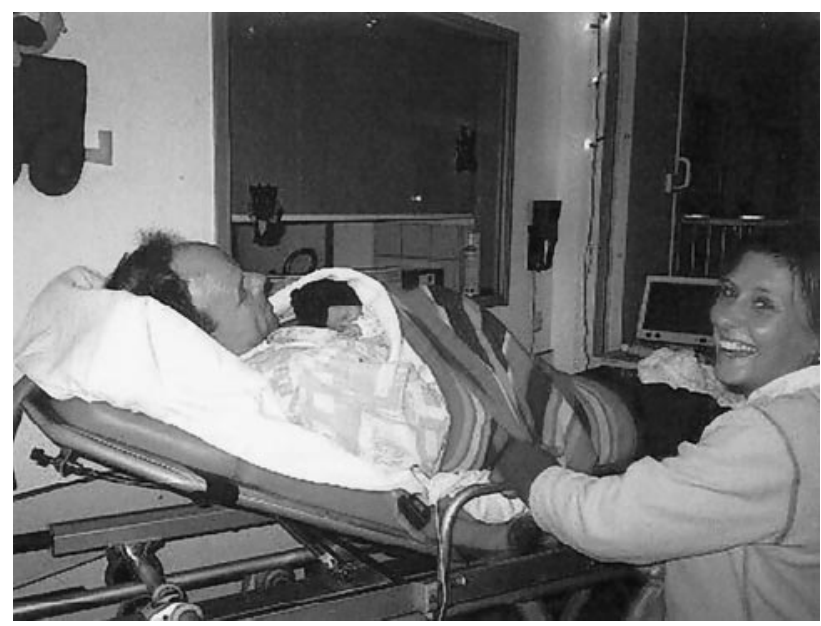

Fig 5. Father and infant after kangaroo transport (back transfer, day $32,1580 \mathrm{~g}, 90 \mathrm{~km}, 80$ minutes).

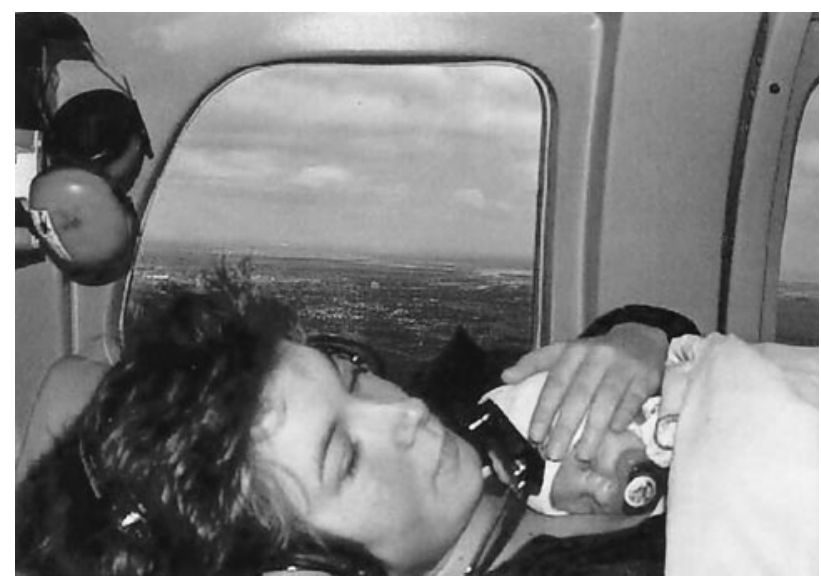

Fig 6. Mother with infant during kangaroo transport in a helicopter (back transfer after abdominal surgery).

transport seems to be safer than the usual incubator transport without safety devices for the infant.

Our preliminary results with 31 kangaroo transports in different settings are promising, and kangaroo transport might be considered as a safe, effective, and inexpensive method of transport, promoting parent-infant bonding. To make a conclusive statement on the advantage of kangaroo transport compared with incubator transport, additional studies with well-defined groups need to be conducted to control for different variables.

All infants in our study were in stable condition before transport. In the near future, kangaroo transports possibly could be done even with neonates who are ventilated, because kangaroo care has been conducted successfully with ventilated infants. ${ }^{18,19}$

\section{ACKNOWLEDGMENTS}

We dedicate this article to our teacher Otwin Linderkamp, who celebrated his 60th birthday in July 2003.

We gratefully acknowledge the help of Susan Ludington in preparing and discussing the initial manuscript. We thank all reviewers for helpful comments and advice.

\section{REFERENCES}

1. Hawgood S, Spong J, Yu VY. Intraventricular hemorrhage. Incidence and outcome in a population of very-low-birth-weight infants. Am J Dis Child. 1984;138:136-139

2. Field D, Milligan D, Skeoch C, Stephenson T. Neonatal transport: time to change? Arch Dis Child. 1997;76:F1-F2

3. Fischer CB, Sontheimer D, Scheffer F, Bauer J, Linderkamp O. Cardiorespiratory stability of premature boys and girls during kangaroo care. Early Hum Dev. 1998;52:145-153

4. Bauer K, Uhrig C, Sperling P, Pasel K, Wieland C, Versmold HT. Body temperatures and oxygen consumption during skin-to-skin (kangaroo) care in stable preterm infants weighing less than 1500 grams. J Pediatr. 1997; 130:240-244

5. Bier JA, Ferguson AE, Morales Y, et al. Comparison of skin-to-skin contact with standard contact in low-birth-weight infants who are breast-fed. Arch Pediatr Adolesc Med. 1996;150:1265-1269

6. Ludington-Hoe SM, Nguyen N, Swinth JY, Satyshur RD. Kangaroo care compared to incubators in maintaining body warmth in preterm infants. Biol Res Nurs. 2000;1:60-73

7. Bauer J, Sontheimer D, Fischer C, Linderkamp O. Metabolic rate and energy balance in very low birth weight infants during kangaroo holding by their mothers and fathers. J Pediatr. 1996;129:608-611

8. Affonso DD, Wahlberg V, Persson B. Exploration of mothers' reactions to the kangaroo method of prematurity care. Neonatal Netw. 1989;7:43-51

9. Feldman R, Eidelman AI, Sirota L, Weller A. Comparison of skin-to-skin (kangaroo) and traditional care: parenting outcomes and preterm infant development. Pediatrics. 2002;110:16-26

10. Chwo MJ, Anderson GC, Good M, Dowling DA, Shiau SH, Chu DM. A randomized controlled trial of early kangaroo care for preterm infants: effects on temperature, weight, behavior, and acuity. Nurs Res. 2002;10: 129-142

11. Conde-Agueldo A, Diaz-Rossello JL, Belizan JM. Kangaroo mother care to reduce morbidity and mortality in low birthweight infants. Cochrane Database Syst Rev. 2000;4:CD002771

12. Sontheimer D, Fischer CB, Scheffer F, Kaempf D, Linderkamp O. Pitfalls in respiratory monitoring premature infants during kangaroo care. Arch Dis Child. 1995;72:F115-F117

13. Sloan NL, Camacho LW, Rojas EP, Stern C. Kangaroo mother method: randomised controlled trial of an alternative method of care for stabilised low-birthweight infants. Maternidad Isidro Ayora Study Team. Lancet. 1994;344:782-785

14. Cattaneo A, Davanzo R, Worku B, et al. Kangaroo mother care for low birthweight infants: a randomized controlled trial in different settings. Acta Paediatr. 1998;87:976-985

15. Charpak N, Ruiz-Pelaez JG, Figueroa de C Z, Charpak Y. Kangaroo mother versus traditional care for newborn infants $\leq 2000$ grams: a randomized, controlled trial. Pediatrics. 1997;100:682-688

16. Ludington-Hoe SM, Swinth JY. Developmental aspects of kangaroo care. J Obstet Gynecol Neonatal Nurs. 1996;25:691-703

17. Charpak N, Ruiz-Pelaez JG, Figueroa de Calume Z. Current knowledge of Kangaroo Mother Intervention. Curr Opin Pediatr. 1996;8:108-112

18. Gale G, Franck L, Lund C. Skin-to-skin (kangaroo) holding of the intubated premature infant. Neonatal Netw. 1993;12:49-57

19. Ludington-Hoe SM, Ferreira CN, Goldstein MR. Kangaroo care with a ventilated preterm infant. Acta Paediatr. 1998;87:711-713 
Kangaroo Transport Instead of Incubator Transport

Dieter Sontheimer, Christine B. Fischer and Kerstin E. Buch

Pediatrics 2004;113;920-923

DOI: $10.1542 /$ peds. 113.4 .920

Updated Information

\& Services

References

Subspecialty Collections

Permissions \& Licensing

Reprints including high-resolution figures, can be found at: http://www.pediatrics.org/cgi/content/full/113/4/920

This article cites 17 articles, 4 of which you can access for free at:

http://www.pediatrics.org/cgi/content/full/113/4/920\#BIBL

This article, along with others on similar topics, appears in the following collection(s):

Office Practice

http://www.pediatrics.org/cgi/collection/office_practice

Information about reproducing this article in parts (figures, tables) or in its entirety can be found online at:

http://www.pediatrics.org/misc/Permissions.shtml

Information about ordering reprints can be found online:

http://www.pediatrics.org/misc/reprints.shtml 